\title{
O Poder Naval na Construção do Poder Marítimo Brasileiro
}

\section{The Naval Power on the Construction of the Brazilian Sea Power}

CAMILA CRISTINA RIBEIRO LUIS*

\section{INTRODUÇÃO}

A estratégia naval consiste no emprego dos recursos à disposição do poder naval visando a atingir fins da estratégia marítima, decorrente da Política Marítima Nacional (PMN). Estratégia marítima foi definida em 1911 por Corbett (2004) como o princípio pelo qual é governada uma guerra em que o mar é o fator substancial, com a finalidade de influenciar os eventos em terra. A estratégia marítima, portanto, direciona o emprego do poder naval, isto é, todas as atividades desenvolvidas pela Marinha envolvendo o mar, considerando o poder marítimo da nação. O poder marítimo é um conceito mais amplo, e perpassa todas as atividades relacionadas ao uso dos mares e oceanos, não somente militares.

Assim, os componentes do poder marítimo são: o poder naval, constituído pelas forças navais, aeronavais e de fuzileiros navais, as bases navais e posições de apoio, a estrutura logística, administrativa e de comando e controle e forças e meios de apoio não orgânicos da Marinha de Guerra (especialmente os meios aéreos), quando vinculados ao cumprimento de sua missão e submetidos a algum tipo de orientação, comando e controle naval; a marinha mercante, conjugada às facilidades, aos serviços e às organizações envolvidas com os transportes marítimos e fluviais; a infraestrutura marítima e hidroviária relacionada aos portos, terminais, meios e instalações de apoio e controle; a indústria naval, constituída pelos estaleiros de construção e reparos; a indústria de materiais de defesa de aprestamento

\footnotetext{
* Doutoranda no Programa de Pós-Graduação em Relações Internacionais San Tiago Dantas (UNESP/UNICAMP/PUC-SP). E-mail: camila.luis@yahoo.com.br.
} 
naval; a indústria de pesca, que inclui terminais, indústria de processamento de pescado e embarcações; as organizações e os meios de pesquisa e desenvolvimento tecnológico de interesse para o uso do mar e águas interiores e de seus recursos; as organizações e os meios de exploração e explotação dos recursos do mar, seu leito e subsolo; o pessoal que desempenha atividades relacionadas com o mar e hidrovias interiores e os estabelecimentos destinados à formação e ao treinamento desse pessoal; mentalidade marítima do povo e da classe política (Pesce, 2006).

O poder naval é a expressão militar do poder marítimo, e se refere a todos os recursos utilizados e atividades realizadas pela Marinha, incluindo a administração em terra. Tais recursos não se restringem somente à expressão da guerra naval, mas abrangem também aspectos relacionados à cooperação técnica, intercâmbio entre oficiais de outras Marinhas, exercícios navais isolados ou em conjunto com outras nações, prestígio e manutenção das tradições e acordos internacionais de boa ordem no mar e liberdade de navegação (Speller, 2008). Neste sentido, o texto aborda, de forma breve, a relação estabelecida entre o poder naval brasileiro e o desenvolvimento e de uma consciência marítima nacional, analisando em um primeiro momento o conceito de maritimidade formulado pelo poder naval para afirmação de um poder marítimo característico da condição geográfica brasileira e, em seguida, o processo de formulação do Planejamento Estratégico da Marinha.

\section{PODER MARÍTIMO E MARITIMIDADE}

Alfred T. Mahan, ao desenvolver a teoria do poder advindo do mar, apontou que alguns elementos geográficos e sociais são necessários para o desenvolvimento do poder marítimo de um determinado Estado. Entre os elementos geográficos, destacam-se o posicionamento, bem como a extensão territorial junto ao litoral; formação física que facilite o acesso ao mar e tamanho da população. Ademais destes elementos geográficos, Mahan enfatizou também a importância de determinadas características sociais expressas na mentalidade da população e das instituições estatais em relação à importância do mar para a prosperidade do Estado (Mahan, 2004).

Assim, ainda que um Estado possua todos os elementos físicos de projeção marítima, não significa que este Estado seja uma potência marítima, pois é também necessário que a nação tenha consciência da potencialidade 
dos recursos de poder provenientes do mar. Esta mentalidade social Vidigal (1985: 121) descreveu como "maritimidade", ou seja, consciência da influência que o mar exerce sobre relações sociais internas: comércio, desenvolvimento econômico, formação de centros populacionais, navegação; e externas: comércio exterior, projeção de poder e defesa.

O Brasil, pela sua localização geográfica e características físicas, configura-se como um país de projeção marítima e continental, sendo que sua formação social estruturou-se a partir do oceano desde o período colonial. Ainda hoje, a maior concentração populacional e econômica encontra-se próxima ao litoral. Entretanto, a disponibilidade de um amplo espaço continental a ser integrado ao eixo litorâneo configurou-se como um grande desafio, despendendo esforço de diversos governos para desenvolvimento da projeção continental do Brasil. Desse modo, elementos de maritimidade presente na época do Império foram sistematicamente perdendo apelo social e governamental em relação à projeção continental. A construção da nova capital federal, Brasília, no interior do Brasil na década de 1950, foi o principal exemplo de desconcentração política do eixo marítimo para o continental.

Neste sentido, alguns autores destacam que o Brasil não se constituiu em um poder marítimo, devido à ausência de uma política governamental que fomentasse o desenvolvimento da maritimidade brasileira.

Apesar de ocupar posição proeminente e ter seu núcleo geo-histórico assentado em torno do Atlântico Sul, o Brasil não se constituiu em um Estado Marítimo, nem sequer desenvolveu uma política sistemática para integrar o oceano na política nacional brasileira, pelo menos até a década de 1970. Uma das razões foi a disposição de um imenso espaço continental aberto à colonização de tal forma que as políticas nacionais não incluíram o mar como elemento primordial ao desenvolvimento da nação. Em consequência disso, não se atribuiu uma importância relevante ao desenvolvimento do Poder Naval, o que fez com que o Brasil se subordinasse às políticas navais das grandes potências, sobretudo a partir da Segunda Guerra Mundial, quando o país caiu sob forte dependência e tutela estratégica da Marinha norte-americana (Penha, 2011: 89).

Como observou Penha (2011), até a década de 1970 não havia uma política sistematizada de desenvolvimento do poder marítimo. Assim, as questões de aproveitamento do Atlântico Sul para as relações internacionais do Brasil perderam significativa importância, situação para a qual contribuiu também a perda de importância estratégica deste oceano, enquanto rota de navegação, após a construção dos canais de Suez e Panamá.

Nesta perspectiva, o Atlântico Sul após a Segunda Guerra Mundial só 
interessava à política externa brasileira no quadro mais geral da defesa do ocidente. Ainda assim, para as potências ocidentais, o Brasil não representava um país estratégico central, uma vez que a dependência do ocidente em relação ao tráfego marítimo na região era pequena, e o perigo de um confronto entre as superpotências no Atlântico Sul parecia improvável. Além disso, os principais pontos de passagem e estrangulamento já estavam controlados pelas potências ocidentais, resultando em um agravamento da situação de marginalização da região em relação à política mundial (Penha, 2011).

Neste contexto, a Marinha do Brasil recebeu a Missão Naval Norte-americana com o objetivo de modernização das técnicas e meios utilizados na guerra antissubmarino, estratégia que foi de fundamental importância durante a Segunda Guerra Mundial. Assim, a concepção estratégica da Marinha do Brasil desenvolvida neste período era basicamente defensiva, com ênfase na guerra antissubmarino, integrada à estratégia de contenção norte-americana para defesa do bloco ocidental. Contudo, o pensamento estratégico da Marinha, cultivado desde sua formação, ainda que não sistematizado, visava ao desenvolvimento do poder marítimo brasileiro, com pleno aproveitamento deste potencial, sustentado pela existência de características físicas e históricas de maritimidade (Vidigal, 1985).

Desde o início da década de 1960, portanto, os oficiais brasileiros vinham criticando a orientação para preponderância das operações antissubmarinas, adotada em conjunto com a Missão Naval Norte-americana. A principal queixa era a recusa, por parte dos Estados Unidos, em considerar as especificidades da Marinha brasileira que, segundo os oficiais, não deveria se restringir à guerra antissubmarina, dado que a Marinha fomentava $o$ desenvolvimento de uma Marinha oceânica para amplo aproveitamento do potencial marítimo do Brasil. Por isso, no início da década de 1970, a Marinha iniciou um processo de revisão quanto aos seus objetivos e metas, com a finalidade de retomar a estruturação de uma Marinha estrategicamente independente e com características oceânicas (Penha, 2011).

O pensamento estratégico da Marinha, visando a maior participação e influência nas decisões estratégicas no Atlântico Sul, com objetivo de estruturar uma componente oceânica com projeção de poder, ressurgiu em meio às modificações do cenário político sul-atlântico, cujas repercussões influenciaram o processo decisório em política externa. Alguns acontecimentos específicos, como o fechamento do Canal de Suez e a consequente valorização da Rota do Cabo e o processo de descolonização de Angola e 
Moçambique nos anos de 1970, contribuíram para valorização da maritimidade brasileira em política externa, uma vez que o Brasil apoiou o fim da colonização portuguesa na África (Saraiva; Gala, 2001). Assim, a inserção internacional do Brasil a partir do mar voltou à pauta da política externa, bem como o consequente papel que o Brasil teria na formulação da segurança regional.

Por outro lado, outros fatores também influenciaram o pensamento estratégico naval, dentre os quais, o principal foi a decisão brasileira de estender o mar territorial para 200 milhas nos anos de 1970, revogando as disposições anteriores. Esta medida teve ampla participação dos oficiais da Marinha, que tomaram parte na elaboração do projeto de lei, sendo, portanto, recebida pelo poder naval com grande euforia, servindo para consolidar seu papel na segurança nacional, por meio do controle que lhe caberia exercer sobre as águas oceânicas (Penha, 2011).

Outra questão importante no cenário estratégico mundial que influenciou no pensamento estratégico da Marinha foi a formalização de um período de menor tensão entre as superpotências nos anos de 1970, motivo que levou os estrategistas navais a acreditar que um conflito global envolvendo o Atlântico Sul fosse pouco provável. Nesse sentido, a preocupação com a segurança sul-atlântica passou a ser determinada não pela ameaça soviética, mas sim pelo crescimento de volume do comércio externo do país e crescente interesse demonstrado pela diplomacia no continente africano (Penha, 2011).

Os debates internacionais em torno da questão antártida também tiveram repercussões sobre o pensamento estratégico naval. Em 1975, o Brasil aderiu ao Tratado da Antártida e, em 28 de outubro de 1976, foram aprovadas, pelo governo brasileiro, as diretrizes gerais para a Política Nacional para Assuntos Antárticos (POLANTAR), como forma de preparar o país para atuar junto aos fóruns internacionais especializados em questões antártidas. A Marinha, então, iniciou o desenvolvimento do Projeto Antártida (PROANTAR), que resultou na construção de uma base de pesquisas na ilha Rei George, cujas atividades iniciaram-se em 1984 (Penha, 2011).

Neste contexto, a Marinha utilizou o discurso de "vazio de poder" (Almeida, 1987), propagado por círculos militares dos países ocidentais no debate sobre as possibilidades de organização de uma Aliança do Atlântico Sul, semelhante à Organização do Tratado do Atlântico Norte (OTAN), para definir as características do poder naval. A situação de vazio de poder ${ }^{1}$ era descrita como ausência de um ator hegemônico regional capaz de conter 
a ameaça soviética no Atlântico Sul, cuja presença na região foi aumentando devido ao agravamento do processo de descolonização em Angola.

Para a Marinha do Brasil, contudo, este vazio gerava uma oportunidade para o poder naval brasileiro exercer maior influência no Atlântico Sul, evitando a ingerência externa e, assim, desenvolver sua componente oceânica. A busca para ocupar o chamado vazio de poder complementava a busca por maior autonomia desenvolvida pela diplomacia durante a Política Externa Independente, do governo de Jânio Quadros e João Goulart, e a política externa conhecida como Pragmatismo Responsável, do governo Geisel. Posteriormente, a percepção de vazio de poder seria questionada pela presença britânica, que, durante o Conflito das Malvinas/Falklands, mostrou-se preponderante no Atlântico Sul.

A partir da década de 1970, portanto, a concepção de defesa coletiva foi sendo substituída por uma preocupação mais específica com a busca de autonomia, orientada pela política externa e priorizada pela expressão diplomática. Esta nova postura desvinculou a Marinha brasileira da estratégia naval norte-americana, expressa inicialmente nas Políticas Básicas e Diretrizes, de 1977, e, posteriormente, com maior profundidade, no Plano Estratégico da Marinha. A sistematização do pensamento estratégico naval nesses documentos tinha como objetivo fomentar a consciência marítima nacional, influenciando as decisões de política externa, auxiliando e complementando a ação diplomática no eixo de inserção internacional brasileira sul-atlântico.

\section{O PLANEJAMENTO ESTRATÉGICO DA MARINHA}

O Planejamento Estratégico da Marinha (PEM) é elaborado considerando duas vertentes de análise: cenários políticos do sistema internacional e o papel que o Brasil desempenhará em diferentes contextos; e a interpretação dos objetivos e potencialidades nacionais em longo prazo. A construção de possíveis cenários estratégicos é delineada a partir da leitura do contexto internacional contemporâneo, tendo em vista a maior ou menor dificuldade de previsibilidade dos acontecimentos. Na década de 1980, por exemplo, nos Relatórios Anuais da Marinha, transparece a preocupação com as instabilidades políticas na área marítima do Atlântico Sul devido ao agravamento das tensões da Guerra Fria na região (Marinha, 1988). Já na década de 1990, foram as mudanças e incertezas deflagradas pela reconfiguração política do sistema internacional que passaram a influenciar as 
definições estratégicas e possíveis cenários projetados pela Marinha.

Por outro lado, é realizada também uma interpretação da política externa e da linha de ação da diplomacia nos diferenciados contextos políticos. Assim, o sistema de planejamento visualizado pela Marinha, em qualquer contexto, enfoca o apoio do poder militar à diplomacia, elemento doutrinário da Marinha. Atualmente, a leitura realizada pela Marinha interpreta como fundamentais os seguintes princípios da ação externa brasileira para os quais a Marinha procura contribuir: busca de solução de controvérsias, fortalecimento dos processos de integração regional e busca de cooperação com outros países que tenham interesses comuns (Longo, 2002).

Deste modo, o Plano Estratégico da Marinha deriva de um processo de definições em diversos níveis, inicialmente delineado pelo Planejamento de Alto Nível da Marinha. Nesse sentido, para abordar o tema PEM, algumas considerações são apresentadas sobre a Sistemática de Planejamento de Alto Nível da Marinha. Segundo Longo (2002), o PEM permite, de forma sequencial, uma ampla análise de assuntos políticos e estratégicos que subsidiam as decisões do almirantado, refletindo-se na aplicação do Sistema do Plano Diretor e possibilitando a administração econômico-financeira da Marinha.

O Planejamento de Alto Nível da Marinha é condicionado pelo Planejamento Nacional de Defesa que, entre 1969 e 1990, era derivado da análise do Conceito Estratégico Nacional. Ademais, também é influenciado pelos aspectos globais da política externa e da estratégia nacionais, incluindo a avaliação de conjuntura nacional e internacional, além do enunciado dos objetivos nacionais e os caminhos ou rumos para atingi-los. Longo (2002: 28) assim descreve o processo de interpretação dos objetivos nacionais pela Marinha:

A interpretação dos interesses e das aspirações nacionais deriva de um processo histórico e emerge, naturalmente, à medida que as necessidades e os interesses se cristalizam na consciência nacional, cabendo aos planejadores e formuladores das políticas somente identificá-los. Dessa maneira, passarão a ser conhecidos os Objetivos Nacionais.

A fase de Planejamento Nacional engloba também avaliação da conjuntura e, atualmente, da Política Nacional de Defesa. A definição dos chamados objetivos nacionais, ainda que interpretados dos documentos elaborados pelo poder político em nível nacional, é uma avaliação especí- 
fica da Marinha que seleciona os elementos essenciais e convenientes com sua postura estratégica, como descreveu o ex-ministro Mauro César Rodrigues Pereira (2002: 33):

Positivamente, antes da Política de Defesa Nacional, não havia uma Política de Defesa. A Marinha já dispunha de documentos formais sobre o assunto, mas o que seria de âmbito nacional era inferido da leitura de diversas fontes, obviamente com a interpretação unilateral inevitável.

A fase seguinte é a chamada Militar, em que são definidos os aspectos militares da política e da estratégia nacional. Esta fase compreende a Avaliação Estratégica Militar da Conjuntura, a Política Militar Brasileira e a Estratégia Militar Brasileira, até a criação do Ministério da Defesa, quando ocorreram mudanças e adaptações na sistemática de planejamento estratégico da Marinha. Contudo, era visível, naquele momento em fins da década de 1990, que a Marinha sentia dificuldade em avaliar os documentos normativos, afirmando que tais documentos, assim como os objetivos em segurança, eram definidos mais precisamente no Conceito Estratégico Nacional, que vigorou entre 1969 e 1990, uma vez que orientava as Hipóteses de Emprego. A Política Militar Brasileira datava de 1993, e a Estratégia Militar estava em constante revisão, sendo que a Estratégia Nacional de Defesa só seria divulgada em 2008. Percebe-se, portanto, a dificuldade de orientação e as lacunas existentes entre a formulação estratégica da Marinha e a Política de Defesa devido à ausência de orientação de política governamental.

Na fase do Planejamento Setorial, que define com precisão os planejamentos de cada força, Marinha, Exército e Aeronáutica, são traçadas as linhas gerais de orientação para emprego de cada força em seus contextos específicos.

O Planejamento de Alto Nível compreende a elaboração de documentos que têm como propósitos a determinação das implicações estratégicas das conjunturas nacional e internacional; a formulação de concepções de emprego do poder naval; e o estabelecimento de objetivos, orientações para o preparo da Marinha. Por fim, o Planejamento de Alto Nível é constituído pelos seguintes documentos: Plano Estratégico da Marinha, Política Básica da Marinha, Orientações do Comandante da Marinha e Orientações Setoriais (LONGO, 2002).

O Plano Estratégico da Marinha (PEM) constitui o ponto de partida de todo planejamento da Marinha e é o documento fundamental que interage 
com a Política Marítima Nacional e a Política Nacional para os Recursos do Mar. O seu propósito é estabelecer o planejamento de longo prazo da Marinha do Brasil, formulando concepções de emprego do poder naval e as orientações para o cumprimento das atribuições subsequentes e das subsidiárias. Posteriormente, o PEM foi adaptado aos novos condicionantes advindos do Ministério da Defesa, tendo, em geral, traços sigilosos à pesquisa. Assim, o PEM, até 2002, era elaborado pelo Estado Maior da Armada desde início da década de 1970, sendo periodicamente atualizado. De forma geral é constituído por três partes distintas: Avaliação Estratégica Naval; Conceito Estratégico Naval; Diretrizes para Planejamento Naval.

1 - Avaliação Estratégica Naval: compreende um exame da situação em nível estratégico sob enfoque naval, no qual são avaliados os fatores mais significativos e relevantes da conjuntura nacional e internacional, avaliando as possíveis implicações com o preparo e a aplicação do poder naval. Para esta avaliação, são considerados os documentos nacionais e militares de alto nível já citados, a legislação nacional, os acordos e tratados internacionais e as políticas e diretrizes governamentais. $\mathrm{O}$ exame e a análise desses documentos e da conjuntura nacional e internacional permitem identificar as atribuições, responsabilidades e envolvimentos da Marinha do Brasil.

2 - Conceito Estratégico Naval: propõe-se, em termos amplos, a formular a concepção de emprego do poder naval em cenários quer de paz, quer das Hipóteses de Emprego em crises, e contemplar as ações a empreender em cada uma delas, ou seja, relacionar as operações ou ações em que os meios serão empregados.

3 - Diretrizes para o Planejamento Naval: orientam os planejamentos decorrentes para o preparo e aplicação do poder naval e para atuação da Marinha nas demais atividades.

A Política Básica da Marinha (PBM) tem o propósito de orientar a Marinha do Brasil para o cumprimento de sua missão. A política contém a Missão da Marinha, os Fatores Condicionantes, os Objetivos da Marinha do Brasil e a orientação geral necessária à formulação das diretrizes para consecução desses objetivos. As Orientações do Comandante da Marinha e Orientações Setoriais visam detalhar como os projetos e ações serão desenvolvidos durante a respectiva gestão e, por isso, são orientações para execução em curto prazo. 
Longo (2002) conclui afirmando que a Sistemática de Planejamento de Alto Nível da Marinha permite identificar os objetivos definidos pela política, a análise de cada um deles, a transposição dos objetivos de nível nacional para o setorial da Marinha, e a elaboração dos documentos, como a Política Básica da Marinha e o Plano Estratégico da Marinha. A Sistemática de Planejamento de Alto Nível da Marinha permite identificar as necessidades para o preparo do poder naval, fruto das atribuições que os representantes da nação, no Legislativo, outorgam à Marinha, além dos encargos decorrentes de acordos e tratados internacionais e das políticas e diretrizes governamentais (LONGO, 2002).

Em suma, o Planejamento de Alto Nível da Marinha tem como objetivo principal definir um conjunto de atividades que procura, considerando as orientações governamentais, fornecer instrumentos que contribuam para o cumprimento da missão da Marinha. Nota-se que o desenvolvimento do poder marítimo é vinculado ao poder naval, sendo este último um atributo do poder marítimo, que, por sua vez, é definido pelo poder político por meio da Política Marítima Nacional (PMN, 1994).

Os militares, portanto, têm exercido influência no processo político de construção e aproveitamento das potencialidades do poder marítimo brasileiro, ocupando um espaço inicialmente destinado ao governo instituído, mas nem sempre rigorosamente delimitado, no qual aos militares caberia somente a atuação profissional clássica de preparar-se para guerra de acordo com os desígnios da política. Contudo, a atuação militar também é influenciada pela cultura e características sociais da nação, ou seja, pela inspiração recebida do povo, das instituições do Estado e das várias organizações societárias.

Flores (1992: 19) afirma que as relações entre sociedade e as instituições militares podem ser definidas como uma “via de mão-dupla”, isto é, os militares influenciam o rumo dos processos políticos da nação além de sua destinação clássica, mas também são influenciados pelas características da sociedade: costumes, crenças, condições de vida, instituições políticas, etc. A força militar sozinha, sem apoio de uma ideologia ou projeto nacional de apelo social, alicerçado sobre uma organização eficiente e sólida, não consegue impor-se.

As Forças Armadas, influenciadas por valores, sensações e perspectivas societárias, são instituições e instrumentos do Estado. [...] Essa condição de criaturas políticas faz com que a existência, o preparo e o emprego das Forças Armadas dependam fundamentalmente da vontade da 
sociedade manifestada através dos seus canais de influência política e da decisão do Estado de as usarem como instrumento para se defender e dar segurança à sociedade, para sobreviver e se impor, mesmo em condições adversas; dependam enfim da existência de claros objetivos políticos, sem os quais não é possível legitimar o uso da força (FLORES, 1992: 30).

Quando os objetivos não são claramente definidos pelo poder político ou simplesmente não existem, devido a fatores históricos que condicionam a percepção por parte do Estado e da sociedade que não há motivo para supor que a segurança possa vir a ser ameaçada, não havendo, portanto, necessidade de organizar a defesa, corre-se o risco de redução da mística que suporta as Forças Armadas, sua neutralidade sociopolítica e sua coesão interna. A mística militar caracteriza-se pela difusão de um sentimento entre as Forças Armadas de uma orfandade funcional e consequente propensão para o aumento da autonomia corporativa militar (Coelho, 2000).

Além disso, no que concerne especificamente à Marinha, a autonomia existente resulta também de um consentimento tácito ou tolerado pela sociedade devido ao conhecimento específico dos recursos marítimos e do meio de aproveitá-los, advindo da profissionalização dos oficiais da Marinha. O desenvolvimento do poder marítimo brasileiro ficou condicionado à pró-atividade da Marinha, que encontrou dificuldade para definição de seu emprego enquanto força militar, apenas identificado na percepção de ameaças.

De forma geral, a expectativa de atuação das Forças Armadas atualmente, interpretados como interesses nacionais, são: manutenção da integridade e unidade do território brasileiro terrestre e marítimo, com seu espaço aéreo e a segurança dos cidadãos, bens e recursos materiais e valores culturais e ambientais nesse território. No que concerne às questões econômicas e correlatas, esse interesse se estende a áreas marítimas que estão economicamente sob jurisdição brasileira, de acordo com o direito internacional a que o Brasil aderiu. Além de manutenção da integridade territorial, outro interesse central para as Forças Armadas é a soberania nacional, traduzida no direito que tem a sociedade brasileira de, por meio dos mecanismos e instrumentos que interpretam e refletem suas aspirações e as transformam em política e ações de governo, decidir e conduzir assuntos brasileiros (Flores, 1992). 


\section{CONSIDERAÇÕES FINAIS}

Para a Marinha do Brasil, o planejamento visando o preparo e emprego do poder naval considera que, para ser útil à dissuasão de pressões militares e de possíveis ingerências externas no entorno regional brasileiro, o poder naval deve ser direcionado para a defesa distante, uma vez que a percepção de ameaça compreendida pela Marinha decorre de interferências externas à região. A defesa distante dificulta que as crises aproximem-se da fronteira marítima brasileira, outra preocupação em defesa.

A operacionalização da defesa distante legitima a construção de elementos característicos de uma marinha oceânica, tais como submarinos, razão pela qual a Marinha considera conveniente a propulsão nuclear, útil para ampliação da dimensão estratégica dissuasória. Ademais, a dimensão oceânica permite projeção de poder, possibilitando demonstrar presença e interesse na área geoestratégica do Atlântico Sul e, consequentemente, inibindo a presença de outras potências. Todos estes fatores, apontados como interesses do poder naval, foram contemplados, posteriormente, na Estratégia Nacional de Defesa, publicada em 2008 e revista em 2012, que enuncia como objetivos da Marinha a negação do uso do mar, o controle das rotas marítimas sul-atlânticas e a projeção de poder. 


\section{NOTA}

1. Almeida (1987), retomando Coutau-Begarie, compreende e critica o debate sobre o Atlântico Sul inserido na questão que a geopolítica não consegue conviver com vazio de poder, reais ou supostos; ela está sempre à procura de potências em perspectiva para preencher seus próprios vácuos teóricos. Para o autor, as questões estratégicas no Atlântico Sul devem priorizar a presença própria dos países da região. 
RBED, v. 2, no 1 , jan./jun. 2015

\section{O PODER NAVAL NA CONSTRUÇÃO DO PODER MARÍTIMO BRASILEIRO}

\section{RESUMO}

O texto aborda a relação estabelecida entre o poder naval brasileiro e o desenvolvimento de uma consciência marítima nacional, analisando em um primeiro momento o conceito de maritimidade, formulado pelo poder naval para afirmação de um poder marítimo característico da condição geográfica brasileira, e, em seguida, o processo de formulação do Planejamento Estratégico da Marinha.

Palavras-chave: Poder Naval. Estratégia. Poder Marítimo.

\section{ABSTRACT}

The text discusses the relationship established between the Brazilian naval power and the development of a national maritime awareness by examining at first the concept of maritimidade, formulated by the naval power to claim a distinctive maritime power of the Brazilian geographical condition, and then the formulation process of the Navy 's Strategic Plan.

Keywords: Naval Power. Strategy. Seapower.

\section{REFERÊNCIAS}

Almeida, Paulo Roberto de. (1987) “Geoestratégia do Atlântico Sul: Uma Visão do Sul”. Política e Estratégia. São Paulo, v.5, n.4, 1987.

Brasil. (1994) "Decreto n. 1265 de 11 de outubro de 1994”. Política Marítima Nacional. Brasília, 1994.

Coelho, Edmundo. (2000) Em busca de identidade. São Paulo: Record.

Corbett, Julian Stafford. (2004) Some Principles of Maritime Strategy. Nova Iorque: Dover.

Flores, Mário C. (1992) Bases para uma Política Militar. Campinas: Ed. Unicamp.

Longo, Airton. (2002) "Planejamento Estratégico da Marinha”. Revista Marítima Brasileira. Rio de Janeiro, v. 122, n. 04/06, 2002. 
Mahan, Alfred T. (2004) "The influence of Sea Power upon History, 1660-1783". Project Gutenberg. Disponível em: www.gutenberg.org/files/13529/13529.txt.

Ministério da Marina. (1988) Relatório Anual da Marinha - 1988. Brasília.

Penha, Eli. (2011) Relações Brasil-África e geopolítica do Atlântico Sul. Salvador: Edufba.

Pesce, Ítalo. (2006) "A Marinha do Brasil e a Ordem Marítima Mundial do século XXI". Revista Marítima Brasileira, Rio de Janeiro, v. 126, n. 7/9, 2006.

Pereira, M. (2002) "As Forças Armadas, a Marinha e o Ministério da Defesa: pensamentos e relatos". Revista Marítima Brasileira. Rio de Janeiro, v. 122, n. 10/12, 2002.

Saraiva, J. F. Sombra; Gala, Irene Vida. (2001) O Brasil e a África no Atlântico Sul: uma visão de paz e cooperação na história da construção da cooperação africanobrasileira no Atlântico Sul. Rio de Janeiro: Editora da Universidade Cândido Mendes.

Speller, I. (2008) "Naval warfare”. In: Jordan, D. et all. Understanding modern warfare. Cambridge.

Vidigal, A. A. F. (1985) A evolução do Pensamento Estratégico Naval Brasileiro. Rio de Janeiro: Biblioteca do Exército. 